\title{
A Survey of the Incidence and Consequences of Invasive Blood Pressure Measuring Errors Caused by Arterial Line Occlusion
}

\author{
Zhinan Zheng, Xiang Liu, Jing Li, Yi Wen, Xiaofei Mo, Sanqing Jin* \\ Department of Anesthesia, The Sixth Affiliated Hospital, Sun Yat-sen University, \\ Guangzhou, China \\ Email: "sanqingjin@hotmail.com
}

Received 29 May 2016; accepted 18 July 2016; published 21 July 2016

Copyright (C) 2016 by authors and Scientific Research Publishing Inc.

This work is licensed under the Creative Commons Attribution International License (CC BY). http://creativecommons.org/licenses/by/4.0/

(c) (7) Open Access

\section{Abstract}

Objective: The objective is to investigate the incidence and consequences of arterial line occlusion during invasive blood pressure monitoring in the form of questionnaire survey. Methods: The questionnaires were randomly distributed to the anesthesiologists who participated the $22^{\text {nd }}$ annual meeting of Chinese society of anesthesiology. The main contents of this survey included the arterial line managing status, the incidence of arterial line occlusion, the effects of arterial line occlusion on the anesthesiologists' therapy and consequences caused by arterial line occlusion. Results: Totally 294 questionnaires were collected, in which 261 questionnaires were valid. In all respondents, $28.3 \%$ expressed that they could not flush arterial line on time, and $95.4 \%$ had experienced flushing arterial line only or sometimes or occasionally when the arterial waveform was not normal. Furthermore, $93.9 \%$ had experienced partial occlusion of the arterial line, and $79.3 \%$ had experienced complete occlusion. According to the serious recall of the respondents, the incidence of partial arterial line occlusion was $17.7 \% \pm 22.0 \%$, and the incidence of complete arterial line occlusion was $3.6 \% \pm 8.1 \%$. For all the respondents, $89.7 \%$ had experienced suspecting arterial line occlusion while real hypotension occurred, $65.1 \%$ had experienced not treating hypotension timely due to this suspicion, and $31 \%$ had experienced serious consequences caused by this suspicion. Conclusion: The incidence of arterial line occlusion is high during invasive blood pressure monitoring, which is a threat to the patients' safety. So, intensive attention should be paid to the arterial line management.

\section{Keywords}

Monitoring, Invasive Blood Pressure, Arterial Line, Patency Condition, Questionnaire Survey

\footnotetext{
*Corresponding author.
}

How to cite this paper: Zheng, Z.N., Liu, X., Li, J., Wen, Y., Mo, X.F. and Jin, S.Q. (2016) A Survey of the Incidence and Consequences of Invasive Blood Pressure Measuring Errors Caused by Arterial Line Occlusion. Open Journal of Anesthesiology, 6, 105-113. http://dx.doi.org/10.4236/ojanes.2016.67018 


\section{Introduction}

Arterial pressure measurement is a reliable procedure in the evaluation of patients' hemodynamics because it gives primary information about the performance of the cardiovascular system and tissue perfusion. There are a variety of methods to measure blood pressure, and they can be divided into non-invasive and invasive measurement according to whether invasive procedures are carried out to the body. Although non-invasive measurement is widely used in clinic, it is not continuous monitoring and is expected to be not accurate in patients with hemodynamic instability, severe hypotension, increased arterial stiffness and obesity [1]-[6]. Invasive blood pressure (IBP) can be measured directly, accurately, and continuously by inserting a cannula in the radial, brachial, femoral, or dorsalis paedis artery and connecting the cannula to a calibrated transducer, which converts blood pressure into an electrical signal. The electrical signal is transmitted to the monitor and then is amplified and displayed as an analog waveform and digital output [7]. IBP is considered to be the gold standard of arterial pressure measurement [8], which provides beat-by-beat measurement especially in patients receiving inotropic or vasoactive drugs, in cases of abrupt changes in blood volume or arterial tone, or those with arrhythmias [2] [3] [9]. IBP provides important guarantee for the patients who are critically ill or undergoing high-risk and major surgery during perioperative period.

A variety of factors can lead to arterial line occlusion during IBP monitoring, which displays that the pressure waveform loses its characteristic landmarks and appears unnaturally smooth, with a diminished or absent dicrotic notch and so on. This may have a great influence on the accuracy of blood pressure monitoring and is also a threat to the patients' safety. There is no report concerning how the arterial line management is carried out in clinic and whether patency condition of arterial line is worth of more attention. This study was designed to investigate the arterial line managing status and the incidence, influence factors and consequences of arterial line occlusion during IBP monitoring by a questionnaire survey, in order to evaluate the importance of the arterial line management on IBP monitoring and perioperative patients’ safety.

\section{Materials and Methods}

\subsection{Design of the Questionnaire}

The relevant literatures were searched with the key words, such as “Invasive blood pressure”, “Arterial line”, "Perioperative management”, “Questionnaire survey” through the Pubmed medical literature retrieval system and the literatures published during 2000-2015 were reviewed. According to these literatures and the experience in clinic, we designed the questionnaire.

The questionnaire consisted of 12 questions (see supporting information), which involved the management of arterial line, the incidence and the influence factors of arterial line occlusion, the effect of arterial line occlusion on the doctors' decision and the serious consequences caused by arterial line occlusion.

\subsection{The Investigated Methods of the Questionnaire Survey}

The questionnaires were randomly distributed to the anesthesiologists who participated the $22^{\text {nd }}$ annual meeting of Chinese society of anesthesiology in Chengdu, China on September $12^{\text {th }}$ and $13^{\text {th }}, 2014$. All the respondents should have a working age more than 1 year in clinical anesthesia. Interns and anesthesiologists who had not engaged in clinical work for 1 year or more were excluded in this survey. Before investigating, the investigators explained the aim and detail instructions of filling the questionnaire to every respondent and the respondent should agree to be investigated and make sure the valid of the answer. All the questionnaires were promptly gotten back after being answered.

\subsection{Data Collection of the Questionnaires}

The questionnaires were collected and centrally kept. The valid questionnaires were selected, which should meet the following requirements: First, all the questions must be answered in clearly writing; second, there was no obvious make do among these answers; third, there was no inherent conflict among these answers.

\subsection{Statistical Analysis}

The general information was descriptively analyzed. Continuous variables were presented as mean \pm standard 
deviation of the mean (SD). Comparison of continuous variables were done with two-tailed nonparametric test of Kruskal-Wallis because of the abnormal distribution and the large SD. Comparison of count variables were done with two-tailed chi-square followed by multiple comparisons of Bonferroni. Statistical analysis was performed using SPSS 16.0 statistical software package (SPSS Inc., Chicago, IL, USA). A value of $P<0.05$ was considered statistically significant.

\section{Results}

\subsection{The Characteristics of the Respondents}

\subsubsection{The Valid Response Rate}

Totally 294 questionnaires were collected, in which 261 questionnaires were valid. The valid response rate was $88.8 \%$.

\subsubsection{Working Age of the Respondents}

Working age of the respondents was 1 year in the minimum and 33 years in the maximum. The average value of working age was $9.9 \pm 7.0$ years. The constituent ratio of the respondents' working age was shown in Table 1 .

\subsubsection{Professional Titles of the Respondents}

The constituent ratio of the respondents' professional titles was shown in Table 1.

\subsubsection{The IBP Monitoring Cases Performed per Month in the Respondents' Serious Recall}

In all the respondents' serious recall, the IBP monitoring cases performed by the respondents per month was less than 5 in the minimum and 300 in the maximum, and sixty-four percent of the respondents performed more than 10 cases per month. The constituent ratio of the amount of IBP monitoring used by the respondents per month was shown in Table 1.

\subsection{The Arterial Line Managing Status in Clinic}

\subsubsection{Types of Fluid for Flushing the Arterial Line}

In all the respondents, $10.3 \%$ indicated they used normal saline for flushing the arterial line, while $89.7 \%$ indicated they used heparinized normal saline as routine.

\subsubsection{Time Interval of Flushing the Arterial Line}

In all the respondents, $41.3 \%$ indicated that they did not flush the arterial line until the arterial waveform was not perfect. The other respondents expressed they flushed the arterial line within a time interval from 15 minutes to 1 hour. The time interval of flushing the arterial line was shown in Table 2.

For the clinical implementation status of flushing arterial line on time, $28.3 \%$ of all the respondents expressed that they could not flush arterial line on time and $95.4 \%$ expressed that they flushed arterial line only or sometimes or occasionally when the arterial waveform was not normal. The results of the two questions were shown in Table 2.

\subsubsection{The Incidence of Arterial Line Occlusion}

In all the respondents, 93.9\% had ever experienced partial occlusion of the arterial line, and $79.3 \%$ had ever experienced complete occlusion of the arterial line during IBP monitoring. According to the serious recall of the

\begin{tabular}{|c|c|c|c|c|c|c|c|c|c|c|c|c|c|c|}
\hline \multirow[b]{2}{*}{$\mathrm{N}$} & \multicolumn{5}{|c|}{ Working age (years) } & \multicolumn{4}{|c|}{ Professional titles } & \multicolumn{5}{|c|}{ The case of IBP monitoring used per month } \\
\hline & $1-5$ & $6-10$ & $11-15$ & $16-20$ & $>20$ & $\begin{array}{c}\text { Chief } \\
\text { physician }\end{array}$ & $\begin{array}{l}\text { Associate } \\
\text { chief } \\
\text { physician }\end{array}$ & $\begin{array}{l}\text { Attending } \\
\text { doctor }\end{array}$ & $\begin{array}{l}\text { Resident } \\
\text { doctor }\end{array}$ & $\geq 100$ & $51-99$ & $21-50$ & $11-20$ & $<10$ \\
\hline 261 & $\begin{array}{c}83 \\
(31.8 \%)\end{array}$ & $\begin{array}{c}79 \\
(30.3 \%)\end{array}$ & $\begin{array}{c}45 \\
(17.2 \%)\end{array}$ & $\begin{array}{c}36 \\
(13.8 \%)\end{array}$ & $\begin{array}{c}18 \\
(6.9 \%)\end{array}$ & $\begin{array}{c}22 \\
(8.4 \%)\end{array}$ & $\begin{array}{c}69 \\
(26.4 \%)\end{array}$ & $\begin{array}{c}94 \\
(36.0 \%)\end{array}$ & $\begin{array}{c}76 \\
(29.2 \%)\end{array}$ & $\begin{array}{c}25 \\
(9.5 \%)\end{array}$ & $\begin{array}{c}18 \\
(6.9 \%)\end{array}$ & $\begin{array}{c}62 \\
(23.8 \%)\end{array}$ & $\begin{array}{c}62 \\
(23.8 \%)\end{array}$ & $\begin{array}{c}94 \\
(36.0 \%)\end{array}$ \\
\hline
\end{tabular}

IBP: invasive blood pressure. Data are expressed as the number of the respondents (percentage that the number accounts for in all the respondents). 
Table 2. The arterial line managing status in clinic.

\begin{tabular}{|c|c|c|c|c|c|c|c|c|c|c|c|c|}
\hline \multirow{2}{*}{$\mathrm{N}$} & \multicolumn{4}{|c|}{$\begin{array}{l}\text { The time interval of flushing } \\
\text { the arterial line }\end{array}$} & \multicolumn{4}{|c|}{$\begin{array}{l}\text { The clinical implementation status } \\
\text { of flushing arterial line on time }\end{array}$} & \multicolumn{4}{|c|}{$\begin{array}{l}\text { The clinical status of flushing arterial } \\
\text { line only when the arterial } \\
\text { waveform was not normal }\end{array}$} \\
\hline & One hour & $\begin{array}{l}\text { Half an } \\
\text { hour }\end{array}$ & $\begin{array}{l}\text { Fifteen } \\
\text { minutes }\end{array}$ & $\begin{array}{l}\text { Only when } \\
\text { necessary }\end{array}$ & Entirely & Basically & $\begin{array}{c}\text { Not } \\
\text { basically }\end{array}$ & $\begin{array}{l}\text { Not } \\
\text { entirely }\end{array}$ & Always & Sometimes & Occasionally & Never \\
\hline 261 & $\begin{array}{c}43 \\
(16.5 \%)\end{array}$ & $\begin{array}{c}67 \\
(25.7 \%)\end{array}$ & $\begin{array}{c}43 \\
(16.5 \%)\end{array}$ & $\begin{array}{c}108 \\
(41.3 \%)\end{array}$ & $\begin{array}{c}26 \\
(10.0 \%)\end{array}$ & $\begin{array}{c}161 \\
(61.7 \%)\end{array}$ & $\begin{array}{c}67 \\
(25.7 \%)\end{array}$ & $\begin{array}{c}7 \\
(2.6 \%)\end{array}$ & $\begin{array}{c}50 \\
(19.1 \%)\end{array}$ & $\begin{array}{c}68 \\
(26.1 \%)\end{array}$ & $\begin{array}{c}131 \\
(50.2 \%)\end{array}$ & $\begin{array}{c}12 \\
(4.6 \%)\end{array}$ \\
\hline
\end{tabular}

Only when necessary: only when arterial waveform was not perfect. Entirely: do as the requirement entirely. Basically: do as the requirement basically. Not basically: not do as the requirement basically. Not entirely: not do as the requirement entirely. Data are expressed as the number of the respondents (percentage that the number accounts for in all the respondents).

respondents, the incidence of partial arterial line occlusion was $17.7 \% \pm 22.0 \%$, and the incidence of complete arterial line occlusion was $3.6 \% \pm 8.1 \%$. The incidence of partial or complete arterial line occlusion in the memory of the respondents with different professional titles was shown in Table 3.

\subsubsection{The Consequences of Invasive Blood Pressure Measuring Errors Caused by Arterial Line Occlusion}

In all the respondents, $89.7 \%$ had the experience of suspicion of arterial line occlusion while real hypotension occurred, $65.1 \%$ had experienced not treating hypotension on time due to this suspicion, and $31 \%$ had experienced serious consequences caused by this suspicion. The answers of the respondents with different professional titles were shown in Table 3.

\subsection{The Causes of Arterial Line Occlusion}

This was multiple-choice question in the questionnaire. In all the respondents, $92.7 \%$ expressed the posture change of the puncture site led to arterial line occlusion and 70.9\% expressed not flushing arterial line on time caused occlusion of arterial line. Forty-nine percent of the respondents expressed the cuff of non-invasive blood pressure monitoring proximal to the puncture site might cause arterial line occlusion, and 3.8\% expressed that some other causes might lead to arterial line occlusion, such as thrombosis, cannula bending, and vascular malformation of the patients.

\subsection{The Attitudes towards Maintaining the Arterial Line Patency by Flushing the Arterial Line or Regulating the Position of the Puncture Site Repeatedly}

In all the respondents $19.5 \%$ expressed these procedures would be a burden to doctors, and $52.5 \%$ hoped these procedures could be avoided. The constituent ratio of the attitudes towards this question was shown in Table 4 .

\section{Discussion}

The word monitor originates from the Latin word "monere", which means "to remind, advise, or warn" [1]. For patients in perioperative period, especially in anesthesia period, there can be a dramatic and rapid change in the vital signs and symptoms. The basic aim of monitoring is to discover the abnormal sign timely and accurately, so the physicians can give effective prevention and treatment to the patients according the monitoring data. During anesthesia, maintenance of adequate tissue perfusion is mandatory, and blood pressure and heart rate are used as the main hemodynamic index [10]. Arterial pressure measurement can supply primary information about the performance of the cardiovascular system and tissue perfusion, so it is an important monitoring index to evaluate the patients' hemodynamics [8] [11].

During the period of anesthesia, there are strong stress factors, such as patients' anxiety, operation stimulus, or visceral traction pain and inhibited factors, such as inhalation anesthetics, intravenous anesthetics or spinal anesthesia, interfering with the normal regulating mechanism of blood pressure, which cause perioperative blood pressure changes even in the easy-operation or short-time surgeries, especially in the complex or long-time surgeries.

Perioperative blood pressure management is a key monitoring factor for anesthetists, as its instability is associated with adverse events. There are $26.4 \%$ of the total adult population suffered from hypertension in the 
Table 3. The incidences of arterial line occlusion in the memory of the respondents and the occurrence of suspicion of arterial line occlusion while real hypotension occurred in the respondents with different professional titles.

\begin{tabular}{|c|c|c|c|c|c|c|}
\hline \multirow{2}{*}{ professional titles } & \multirow{2}{*}{$\mathrm{N}$} & \multicolumn{2}{|c|}{$\begin{array}{l}\text { The incidences of arterial line occlusion in the } \\
\text { memory of the respondents }\end{array}$} & \multicolumn{3}{|c|}{$\begin{array}{l}\text { The occurrence of suspicion of arterial line } \\
\text { occlusion while real hypotension occurred }\end{array}$} \\
\hline & & Partial occlusion & Complete occlusion & A & B & $\mathrm{C}$ \\
\hline Chief physician & 22 & $15.3 \pm 22.0$ & $4.3 \pm 6.6$ & 21 & 12 & 10 \\
\hline $\begin{array}{l}\text { Associate chief } \\
\text { physician }\end{array}$ & 69 & $13.3 \pm 16.1$ & $2.6 \pm 3.5$ & 57 & 52 & 26 \\
\hline Attending doctor & 94 & $18.6 \pm 23.9$ & $2.7 \pm 4.7$ & 87 & 63 & 32 \\
\hline Resident doctor & 76 & $21.1 \pm 23.8$ & $4.0 \pm 6.9$ & 69 & 43 & $13^{*}$ \\
\hline
\end{tabular}

Data of the incidence are expressed as the percentage. Data of suspicion of arterial line occlusion while real hypotension occurred in the respondents are expressed as the number of the respondents with the specific professional title in every given answer. A: one had the experience of suspicion of arterial line occlusion while real hypotension occurred. B: one had experienced not treating hypotension on time due to this suspicion. C: one had experienced serious consequence caused by this suspicion. ${ }^{*} \mathrm{P}<0.05$ compared with Associate chief physician.

Table 4. The attitudes towards maintaining the arterial line patency by flushing the arterial line or regulating the position of the puncture site repeatedly.

\begin{tabular}{cccc}
\hline N & $\begin{array}{c}\text { These procedures would be a } \\
\text { burden to clinical work }\end{array}$ & $\begin{array}{c}\text { It did not matter to do these } \\
\text { procedures }\end{array}$ & $\begin{array}{c}\text { It could be better if these } \\
\text { procedures could be avoided }\end{array}$ \\
\hline 261 & $51(19.5 \%)$ & $73(28.0 \%)$ & $137(52.5 \%)$ \\
\hline
\end{tabular}

Data are expressed as the number of the respondents (percentage that the number accounts for in all the respondents).

world [12]. Perioperative hypertension occurs in $25 \%$ of hypertensive patients who undergo surgery [13]. It is an independent predictive factor of cardiac adverse events in noncardiac surgery [14]. In patients with known coronary artery disease or at high risk for coronary artery disease who are undergoing noncardiac surgery, preoperative hypertension increases risk for death by 3.8 times [15]. Isolated systolic hypertension is also associated with a $40 \%$ increase in perioperative cardiovascular morbidity in coronary artery surgery patients [16]. Perioperative hypertension increases blood loss, myocardial ischemia, and cerebrovascular events [10]. Meanwhile, intraoperative hypotension is one of the most encountered factors associated with death related to anesthesia [17]. There is no widely accepted definition of intraoperative hypotension, resulting in different incidences being reported across studies. Bijker et al. found that intraoperative hypotension occurs with anesthesia administration in 5\% - 99\% of patients [18]. For cesarean delivery under spinal anesthesia, the incidence of hypotension varies between $7.4 \%$ and $74.1 \%$ in accordance with various definitions of hypotension [19]. A decrease of $40 \%$ in MAP or an episode of a MAP $<50 \mathrm{mmHg}$ during surgery is associated with cardiac events in high-risk patients [14]. Even short episodes of intraoperative MAP of $<55 \mathrm{mmHg}$ are associated with acute kidney injury and myocardial injury after a noncardiac surgery [20].

To sum up, optimal perioperative blood pressure management appears to be a key factor for patients' care, which depends on the timely and effective monitoring of blood pressure. IBP monitoring is widely used in anesthesia and intensive care unit, and the patency condition of the arterial line is an important factor to ensure the timely and accurate monitoring of blood pressure. The survey showed, in all the respondents, $93.9 \%$ had ever experienced partial occlusion of the arterial line, and $79.3 \%$ had ever experienced complete occlusion of the arterial line during IBP monitoring. According to the serious recall of the respondents, the incidence of partial arterial line occlusion was $17.7 \% \pm 22.0 \%$, and the incidence of complete arterial line occlusion was $3.6 \% \pm$ $8.1 \%$. Occlusion of arterial line would be a great influence on the accuracy of blood pressure monitoring and a threat to the patients' safety. From all the respondents, $89.7 \%$ of them had the experience of suspicion of arterial line occlusion while real hypotension occurred, $65.1 \%$ of them had experienced not treating hypotension on time due to this suspicion, and 31\% of them had experienced serious consequence caused by this suspicion. So ensuring the patency condition of the arterial line during IBP monitoring should be got further attention in clinical work.

For the high incidence of arterial line occlusion, which is a threat to the safety of patients, it is necessary to learn about the causes. This investigation showed the posture change of the puncture site was an important fac- 
tor causing arterial line occlusion. While not flushing arterial line timely also contributed to arterial line occlusion. Our survey showed that, in all the respondents, 28.3\% expressed that they could not flush arterial line on time, and 95.4\% expressed that they flushed arterial line only or sometimes or occasionally when the arterial waveform was not normal. Seventy-two percent of all the respondents expressed maintaining the arterial line patency by flushing the arterial line or regulating the position of the puncture site repeatedly would be a burden to doctors or hoped these procedures could be avoided. In addition, $89.7 \%$ of the respondents indicated they used heparinized normal saline for flushing arterial line as routine. A dilute concentration of heparin (1 to 2 units heparin/mL saline) added to the flush solution to reduce the incidence of catheter thrombosis was mentioned in Miller's Anesthesia, but it was reminded that this practice increased the risk of heparin-induced thrombocytopenia [21]. Tuncali and Whitta both demonstrated that there was no significant difference between heparinized and nonheparinized flush solutions on the maintenance of radial artery catheter patency [22] [23]. Miller's Anesthesia pointed out that the rapid flushing should be used to restore the dynamic response characteristics of the pressure monitoring system, which otherwise slowly deteriorated over time [21]. While, flushing arterial line timely for maintenance of arterial line patency was not seriously carried out in clinic, which might due to the fact that the clinicians did not pay intensive attention to flushing arterial line timely and the serious consequences caused by that, and the heavy workload of the clinicians might be another important cause.

Our study is the first to investigate the incidence and consequences of IBP measuring errors caused by arterial line occlusion in the form of questionnaire survey. The respondents of this survey were the anesthesiologists who participated the $22^{\text {nd }}$ annual meeting of Chinese society of anesthesiology. In all the respondents, $68.2 \%$ had a working age of 6 years or more longer, and 70.8\% had a professional title of attending doctors or higher. All of the respondents were active in anesthesia clinical work with a wealth of clinical experience, so there should be high reliability of the answers of these questionnaires. In this survey, the questionnaires were randomly distributed, promptly collected and seriously sorted. Meanwhile all the questionnaires were filled out anonymously, so the respondents did not have any relevant concerns. All the above ensured the authenticity and reliability of this survey.

The major limitation of the study was that the cases of IBP monitoring used per month for every respondent and the incidence of arterial line occlusion were detected by serious recall of the respondent, and there would be some discrepancy between the respondents’ memory and clinic records. So we explained the aim and detail instructions of filling the questionnaire to every respondent before investigating to make sure the valid of the answer close to the clinic records by the largest extent. Except working age and professional titles, other factors, such as gender or educational background might also affect the IBP monitoring, which would be a content of our future work.

\section{Conclusion}

The incidence of arterial line occlusion is high during IBP monitoring in clinical anesthesia, which has a great influence on the accuracy of blood pressure monitoring and is also a threat to the patients' safety. So, intensive attention should be paid to the arterial line management during IBP monitoring.

\section{Acknowledgements}

We greatly thank associate professor Jinxin Zhang in Department of Medical Statistics and Epidemiology in School of Public Health in Sun Yat-sen University (Guangzhou, China) for providing guidance on statistical analysis. We thank Ting Pang, Hongbin Feng, Dongxue Li, Fei Li, Zijia Li, Yanna Pi, Shanmei Wu, Xiang Chen and Xiaoxiao Wei in our department for their valuable work for designing the and collecting the questionnaire. We thank the respondents for their participation of the investigation.

\section{Declaration of Interests}

All authors have no interests to be declared.

\section{References}

[1] Andrews, F.J., and Nolan, J.P. (2006) Critical Care in the Emergency Department: Monitoring the Critically Ill Patient. Emergency Medicine Journal, 23, 561-564. http://dx.doi.org/10.1136/emj.2005.029926 
[2] Chatterjee, A., DePriest, K., Blair, R., Bowton, D. and Chin, R. (2010) Results of a Survey of Blood Pressure Monitoring by Intensivists in Critically Ill Patients: A Preliminary Study. Critical Care Medicine, 38, 2335-2338. http://dx.doi.org/10.1097/CCM.0b013e3181fa057f

[3] Dellinger, R.P., Levy, M.M., Rhodes, A., et al. (2013) Surviving Sepsis Campaign: International Guidelines for Management of Severe Sepsis and Septic Shock: 2012. Critical Care Medicine, 41, 580-637. http://dx.doi.org/10.1097/CCM.0b013e31827e83af

[4] Pickering, T.G., Hall, J.E., Appel, L.J., et al. (2005) Recommendations for Blood Pressure Measurement in Humans and Experimental Animals: Part 1: Blood Pressure Measurement in Humans: A Statement for Professionals from the Subcommittee of Professional and Public Education of the American Heart Association Council on High Blood Pressure Research. Hypertension, 45, 142-161. http://dx.doi.org/10.1161/01.HYP.0000150859.47929.8e

[5] Bur, A., Herkner, H., Vlcek, M., et al. (2003) Factors Influencing the Accuracy of Oscillometric Blood Pressure Measurement in Critically Ill Patients. Critical Care Medicine, 31, 793-799.

http://dx.doi.org/10.1097/01.CCM.0000053650.12025.1A

[6] Araghi, A., Bander, J.J. and Guzman, J.A. (2006) Arterial Blood Pressure Monitoring in Overweight Critically Ill Patients: Invasive or Noninvasive? Critical Care, 10, R64. http://dx.doi.org/10.1186/cc4896

[7] McGhee, B.H. and Bridges, E.J. (2002) Monitoring Arterial Blood Pressure: What You May Not Know. Critical Care Nurse, 22, 60-64, 66-70, 73.

[8] Antonelli, M., Levy, M., Andrews, P.J., et al. (2007) Hemodynamic Monitoring in Shock and Implications for Management. International Consensus Conference, Paris, France, 27-28 April 2006; Intensive Care Medicine, 33, 575-590. http://dx.doi.org/10.1007/s00134-007-0531-4

[9] Lehman, L.W., Saeed, M., Talmor, D., Mark, R. and Malhotra, A. (2013) Methods of Blood Pressure Measurement in the ICU. Critical Care Medicine, 41, 34-40. http://dx.doi.org/10.1097/CCM.0b013e318265ea46

[10] Lonjaret, L., Lairez, O., Minville, V. and Geeraerts, T. (2014) Optimal Perioperative Management of Arterial Blood Pressure. Journal of Integrated Blood Pressure Control, 7, 49-59. http://dx.doi.org/10.2147/IBPC.S45292

[11] Winters, M.E., McCurdy, M.T. and Zilberstein, J. (2008) Monitoring the Critically Ill Emergency Department Patient. Emergency Medicine Clinics of North America, 26, 741-757. http://dx.doi.org/10.1016/j.emc.2008.06.001

[12] Kearney, P.M., Whelton, M., Reynolds, K., Muntner, P., Whelton, P.K. and He, J. (2005) Global Burden of Hypertension: Analysis of Worldwide Data. The Lancet, 365, 217-223. http://dx.doi.org/10.1016/S0140-6736(05)70151-3

[13] Varon, J. and Marik, P.E. (2008) Perioperative Hypertension Management. Vascular Health and Risk Management, 4, 615-627.

[14] Kheterpal, S., O’Reilly, M., Englesbe, M.J., et al. (2009) Preoperative and Intraoperative Predictors of Cardiac Adverse Events after General, Vascular, and Urological Surgery. Anesthesiology, 110, 58-66. http://dx.doi.org/10.1097/ALN.0b013e318190b6dc

[15] Browner, W.S., Li, J. and Mangano, D.T. (1992) In-Hospital and Long-Term Mortality in Male Veterans Following Noncardiac Surgery. JAMA, 268, 228-232. http://dx.doi.org/10.1001/jama.1992.03490020076034

[16] Aronson, S., Boisvert, D. and Lapp, W. (2002) Isolated Systolic Hypertension Is Associated with Adverse Outcomes from Coronary Artery Bypass Grafting Surgery. Anesthesia and Analgesia, 94, 1079-1084. http://dx.doi.org/10.1097/00000539-200205000-00005

[17] Lienhart, A., Auroy, Y., Pequignot, F., Benhamou, D., Warszawski, J., Bovet, M. and Jougla, E. (2006) Survey of Anesthesia-Related Mortality in France. Anesthesiology, 105, 1087-1097. http://dx.doi.org/10.1097/00000542-200612000-00008

[18] Bijker, J.B., van Klei, W.A., Kappen, T.H., van Wolfswinkel, L., Moons, K.G. and Kalkman, C.J. (2007) Incidence of Intraoperative Hypotension as a Function of the Chosen Definition: Literature Definitions Applied to a Retrospective Cohort Using Automated Data Collection. Anesthesiology, 107, 213-220. http://dx.doi.org/10.1097/01.anes.0000270724.40897.8e

[19] Klohr, S., Roth, R., Hofmann, T., Rossaint, R. and Heesen, M. (2010) Definitions of Hypotension after Spinal Anaesthesia for Caesarean Section: Literature Search and Application to Parturients. Acta Anaesthesiologica Scandinavica, 54, 909-921. http://dx.doi.org/10.1111/j.1399-6576.2010.02239.x

[20] Walsh, M., Devereaux, P.J., Garg, A.X., et al. (2013) Relationship between Intraoperative Mean Arterial Pressure and Clinical Outcomes after Noncardiac Surgery: Toward an Empirical Definition of Hypotension. Anesthesiology, 119, 507-515. http://dx.doi.org/10.1097/ALN.0b013e3182a10e26

[21] Miller, R.D., Cohen, N.H., Eriksson, L.I., Fleisher, L.A., Wiener-Kronish, J.P. and Young, W.L. (2014) Miller's Anesthesia. Elsevier Inc., Philadelphia, 1347-1361.

[22] Tuncali, B.E., Kuvaki, B., Tuncali, B. and Capar, E. (2005) A Comparison of the Efficacy of Heparinized and Nonhe- 
parinized Solutions for Maintenance of Perioperative Radial Arterial Catheter Patency and Subsequent Occlusion. Anesthesia and Analgesia, 100, 1117-1121. http://dx.doi.org/10.1213/01.ANE.0000146963.19543.D4

[23] Whitta, R.K., Hall, K.F., Bennetts, T.M., Welman, L. and Rawlins, P. (2006) Comparison of Normal or Heparinised Saline Flushing on Function of Arterial Lines. Critical Care and Resuscitation, 8, 205-208. 


\section{Supporting Information}

Questionnaire of the incidence and consequences of invasive blood pressure measuring errors caused by arterial line occlusion

1 Your basic information

1.1 Your hospital

Province: City: Hospital:

1.2 Your working age:

1.3 Your professional title:

a. Chief physician b. Associate chief physician c. Attending doctor d. Resident doctor

1.4 The number of cases in which IBP monitoring was used per month in your memory:

2 The arterial line managing status in clinic

2.1 Type of fluid for flushing the arterial line

a. Normal saline b. heparinized normal saline c. Other

2.2 Time interval of flushing the arterial line

a. About 1 hour b. About half an hour c. About fifteen minutes d. Flush the arterial line only when arterial waveform was not perfect

2.3 Whether you could flush the arterial line on time?

a. Do as the requirement entirely. b. Do as the requirement basically. c. Not do as the requirement basically.

d. Not do as the requirement entirely

2.4 whether you flushed arterial line only when the arterial waveform was not normal?
a. Always
b. Sometimes
c. Occasionally
d. Never

3. The incidence of arterial line occlusion in the impression of the respondents and the occurrence of suspicion of arterial line occlusion while real hypotension occurred

3.1 In your memory, the incidence of partial arterial line occlusion was ___ $\%$, and the incidence of complete arterial line occlusion was__ $\%$.

3.2. Did you have the experience of suspicion of arterial line occlusion while real hypotension occurred?

a. Yes b. No

3.3 Did you have experience not treating hypotension on time due to the above suspicion?

a. Yes b. No

3.4 Did you have experience serious consequence caused by the above suspicion?

a. Yes b. No

3.5 The causes of arterial line occlusion you had experienced (multiple-choice question)

a. The posture change of the puncture site

b. Not flushing arterial line on time

c. Inflating cuff of non-invasive blood pressure monitoring proximal to the puncture site

d. Some other causes

3.6 Your attitude towards maintaining the arterial line patency by flushing the arterial line or regulating the position of the puncture site repeatedly.
a. It would be a burden to clinical work
b. It did not matter to do these procedures
c. It could be better if these procedures could be avoided 


\section{Submit or recommend next manuscript to SCIRP and we will provide best service for you:}

Accepting pre-submission inquiries through Email, Facebook, LinkedIn, Twitter, etc.

A wide selection of journals (inclusive of 9 subjects, more than 200 journals)

Providing 24-hour high-quality service

User-friendly online submission system

Fair and swift peer-review system

Efficient typesetting and proofreading procedure

Display of the result of downloads and visits, as well as the number of cited articles

Maximum dissemination of your research work

Submit your manuscript at: http://papersubmission.scirp.org/ 